\title{
Thoracic Sympathetic Nerve Trunk
}

National Cancer Institute

\section{Source}

National Cancer Institute. Thoracic Sympathetic Nerve Trunk. NCI Thesaurus. Code C52827.

Gang lionated nerve cords that extend on either side of the thoracic portion of the vertebral column comprising primarily ascending and descending pregang lionic sympathetic fibers and visceral afferent fibers. 